\title{
The Requirements for Developing the Programs and Designing a Foreign Language Teaching Syllabus for the Students Following the Education Internationalization
}

\author{
Elena V. Grigoryeva ${ }^{1}$, Elena G. Khrisanova ${ }^{2}$, Olga G. Maksimova ${ }^{2}$, Lilia A. Metelkova ${ }^{2}$, Marina B. Kozhanova ${ }^{2}$, \\ Rinat G. Gatin ${ }^{1}$, Lyudmila V. Kuznetzova ${ }^{2}$ \& Zyamil G. Nigmatov ${ }^{1}$ \\ ${ }^{1}$ Kazan Federal University, Kazan, Russia \\ ${ }^{2}$ Chuvash State Pedagogical University named after I. Y. Yakovlev, Cheboksary, Russia \\ Correspondence: Elena V. Grigoryeva, Kazan Federal University, Kremlyovskaya Street 18, Kazan, 420008, \\ Russia. E-mail: amalia565@mail.ru
}

Received: January 19, 2014

Accepted: February 22, 2015 Online Published: March 25, 2015

doi:10.5539/res.v7n5p124

URL: http://dx.doi.org/10.5539/res.v7n5p124

\begin{abstract}
Russia's joining international economic and educational community, expanding multilateral ties with the countries of the united Europe and the United States, the process of internationalization which have affected all major spheres of modern society including education mounts challenges for the design and implementation of the teaching foreign language syllabus. Therefore, this article aims to identify and study the requirements for the development and design of the foreign language teaching syllabus inclusive of the education internationalization compliant with the social order and determined by the linguistic world dynamics, reflecting a vivid communicative, person-oriented and professional focus of teaching a foreign language. The article submissions may be useful to the teachers of "Foreign Language" disciplines as well as for the students of the teachers' training universities.
\end{abstract}

Keywords: foreign language teaching, students, internationalization, developing the programs, designing syllabus

\section{Introduction}

The current stage of teaching a foreign language requires a fundamental revision of its learning and teaching issues which in turn imposes an idea of adjusting the discipline syllabus in balance with a social order and modern tendencies in language education that imply its humanization providing the development of language teaching while focusing on human values, creating conditions for the utmost satisfaction of the future specialists' need in self-actualization, self-realization in personal, spiritual, social and professional development; humanitarization which implies the value-based apprehension of the human civilization experience and planetary thinking development; the transition to a multi-level education structure that leads to a hierarchy of the objectives in foreign language teaching within the Bachelor-Master degrees; standardization involves the growth of national requirements for basic language education syllabus that is compulsory for all the students; internationalization and globalization of language education; the aspiration of language education to consolidate national traditions and consider the tendencies to interact in the global educational environment (Lopatina et al., 2015); focus on the epistemological teaching model which is based on cognitive tools and technologies of learning an academic discipline that develop the urges of productive and creative nature; the transition to a communication-oriented teaching where the major change is that the object of education is not the language and its expressive possibilities by themselves, but also the process of practical application of the linguistic, psychological and socio-cultural knowledge required for the effective cross-cultural communication (Grigoryeva et al., 2015; Lopatina et al., 2015; Lopatina et al., 2015; Masalimova et al., 2014).

In the context of education globalization and internationalization one of the ways of updating the language education syllabus is "planetary globalism" which is characterized by:

- The focus on the development of an interrelated policy in the field of culture, education, science and communication in order to ensure a balance between the progress, intellectual development and moral endeavor of the individuality. The basic concepts that comprise language education should become the values and culture, 
spirituality and morality, freedom and responsibility;

- A holistic approach to integration of the international aspect into all levels and forms of language education, the study of the topics affecting global mankind problems, interdependence between nations and peoples, peace education, peace-making and human rights education by means of leaning languages and cultures, etc. that assumes introducing into the teaching foreign languages syllabus a value aspect in addition to factual, linguistic and cultural ones; at the same time along with the socio-cultural portrait of the country and the native-speaker of the target language the educators should consider the current issues relevant to multilingual and multicultural world (in particular, the problems of racism, discrimination inclusive of the national background, ethnocentrism, national extremism, protecting rights of ethnic minorities, as well as environmental, economic and demographic problems and possible ways of their non-violent resolution and others) (Galskova, 2000; Sakhieva et al., 2015; Ivanov et al., 2015; Shaidullina et al., 2015; Gutman et al., 2014; Valeeva et al., 2015).

\section{Literature Review}

In foreign language practice there are several types of syllabi. Each being designed in accordance with a specific method or approach to learning a foreign language presents its conceptual issues and implements practical accomplishment of this method or approach.

The foreign experts in a syllabus design Nunan (1998), Hutchinson (1997) and others declare that the availability of various types of syllabi does not mean that one or another type must be compulsory and assigned to a particular method of teaching. Some academic programs specify the themes, functions and terms subject to learning; others do not require any selection of the language material but contain a complete list of the communicative tasks to be performed. The tasks are arranged in a particular sequence and graded in difficulty. In practice, any working syllabus represents itself a combination of several types of syllabi (mixed syllabus, multi-strand syllabus, etc.). Hutchinson and Waters (1997) bring notice that the various syllabus types are the ways of describing the teaching process. Any kind of communication has three levels: structural, functional levels and the level of discourse. These levels do not exclude, but complement each other and each of them should be reflected in the syllabus while designing.

The foreign researchers Hutchitson and Waters (1997) submit the following classification of the syllabus types according to: 1) the degree of compulsion: a priori syllabus, a posteriori syllabus, negotiated syllabus; 2) the focus on the learning objective: learning-centered syllabus, skills-centered syllabus; 3 ) the employed educational unit: structural / grammatical / language-centered syllabus, content-based (topic-based / theme-based, situational syllabus), functional-notional syllabus, lexical syllabus, task-based / procedural syllabus.

The syllabus a priori (a priori syllabus, a posteriori syllabus) involves a pre-selection and organization of the material, the development of the course before the teaching process starts. It serves a ground for further planning of the course, lessons and assignments for the students. This type of syllabus is usually contrasted to a posteriori one that is not planned in advance, designed in the course of retrospective analysis. At the end of the course the syllabus fixes the employed language material and assignments. Therefore, a posteriori syllabus is sometimes called are trospective syllabus.

Anegotiated syllabus is discussed and then designed together with the students in the process of teaching and learning following the analysis and specific communication needs of the learners. It should be noted that this syllabus goes through the same stages of development as the traditional one, namely: planning - the analysis of the specific language needs of the students, defining the educational goals and objectives; implementation of the program - the choice of the teaching methods and corresponding procedures, the choice of the teaching materials; evaluation and adjustment of the syllabus during the process of training and at the end of the course. The key difference of this type of syllabus from the traditional ones is that it is developed jointly with the students who are actively involved in solving the issues related to the syllabus that has a significant impact on the entire process of developing the syllabus and its implementation (Nunan \& Lamb, 1997).

The syllabus that is focused on the process of learning, mastering the language is called the learning-centered syllabus. By contrast with the person-centered approach to teaching relating to the syllabus design it is offered to apply a term "learning-centered" (Hutchinson \& Waters, 1997). This allows to shift the focus from the student's interests and desires which are not always justified to the learning process, to how the students' communicative competence is being formed. The syllabus of this type should be dynamic, include compensatory mechanisms that would allow if necessary to vary, rebuild the course or technique in terms of the identified characteristics, needs and interests of the students which were not (and could not be) taken into account when designing the syllabus or have changed during the course of training. It should be mentioned that the syllabi focused on the process of teaching provide for a more efficient formation of the students' communicative competence. 
The skills-centered syllabus implies the skills the students should acquire during the training period. The syllabus of this type aims at the formation of one, some or all speaking skills. This syllabus may intend to form both speaking skills and other specific skills. The example of a specific skill can be the skill to learn that may have abridging character and contribute to the speaking skills proficiency in learning process. The researchers point that such types of syllabus are focused on the product. We should mention their rigidity as a disadvantage which does not allow to take into account the changing priorities appearing in the teaching process as well as the students' wishes and interests (Jordan, 1997).

The content-based syllabus is developed on the basis of the content-based approach to teaching. A syllabus of this type is based not on structural or functional language units but on a larger speech units that bear a meaning at the level of text. It is known that teaching in terms of separate sentences often does not provide the targeted result, as the meaning of the utterance can be understood or expressed only within the context, that is, at the level of text. The national practice applies the functionally - contextual approach to building the syllabus when the syllabus reflects not only the speech functions and structures of their expression, but also the situations and themes, i.e. these mantic units of a higher level.

Within the content-based syllabus we can distinguish the situational syllabus; topic-based syllabus / theme-based syllabus. The syllabus of the first type are based on the situational approach to teaching. Unlike other programs that apply the situations only for drilling linguistic phenomena, the syllabus of this type involves the situations as the teaching units which means their selection, arrangement and further application to develop the students' speaking skills. The second type of syllabus is based on the topics and relevant lexical and grammatical material that should be learned during the training period. In practice, there is a combination of these two types of syllabi into a thematic-situational one since every topic includes some subtopics and situations which constitute grounds for teaching (Kolesnikova \& Dolgina, 2001).

The syllabus of the functionally-contextual type is called the functional syllabus / notional-functional syllabus (NFS). Ithas been developed on the basis of the functional approach implying not a systemic but functional arrangement of the teaching material according to the speech functions. The particular attention is drawn to the implication of a language phenomenon rather than to its shape. The foremost characteristic of these syllabus is to use speech functions and notions as a teaching unit thereby providing communication and giving effect to the speech intentions of the trainees. Unlike the structural syllabus, the syllabi that are based on the functional principle include a list of communicative functions (request, offer, disagreement, etc.) reflecting the speaker's communicative intention and linguistic structures which help to serve these functions in communication. These syllabi also contain a list of notions that the students should perceive. They are divided into two groups: the general notions and specific notions. The general notions include the concepts of place, time, quantity, quality, and others. The specific notions imply the general concepts in a particular situation or within a certain topic. They are usually grouped under the headings like "Business and money", "Market and customers" and others (Odlin, 1994).

The lexical syllabus is developed in accordance with the lexical approach as opposed to the syllabi based on grammar. The authors of the lexical approach to the syllabus development have followed the idea that all notions are expressed not so much by the grammatical structures and phenomena as by lexical means which seem more important in producing the utterances (Willis, 1990). In accordance with the lexical approach to designing the syllabi the authors offer to include as the language material not the conjunctive mood, for example, or tense verb forms but such lexical units as should, would, have written and so on, that later will be applied in a variety of contexts that reflect their meaning.

The syllabus of the structural (grammar) type (structural syllabus / grammatical syllabus/ language-centered syllabus) is being developed in accordance with the structural approach based on the provisions of structural linguistics and behavioral trend in psychology. This syllabus is designed on the system description of the language and includes as the language material such categories as tense verb forms, the article and others. Such syllabus can also be designed on grammar structures that present themselves as isolated sentences typical for the particular sentence patterns. The selected language material is arranged in a logical order which is determined by such factors as frequency, currency, degree of difficulty and others, or a combination of them. Teaching within the structural syllabus is mainly based on rules and language exercises. It is known that applying such an approach the students master the language but have difficulties in using it in communication (Ellis, 1997).

The syllabus based on the communicative tasks (task-based syllabus / procedural syllabus) is a program of an analytical type and is focused on the process of learning. The educational unit is a communicative task performing which the students acquire communicative competence in various kinds of speech activity. Unlike 
the syllabi focused on a product, the characteristic feature of this program is the absence of any kind of purposeful selection and organization of the linguistic material and methods of instruction. The syllabus offers a list of communicative tasks, such as: to draw a chart or a table basing on the material that has been read or listened to; follow the commands of a classmate; react with gestures and facial expressions to the text that has been listened; find out the necessary information using any available means of communication-verbal and non-verbal. The tasks are presented in a certain sequence which reflects the order of their acquisition. Often this sequence is based on the principle "from simple to complicated". The question of designing the syllabi of this type as well as the method of communication challenges in its extreme understanding remains debatable.

The foreign researchers (F. Dublin, D. Newnan, T. Hutchinson, A. Waters) suppose that any active syllabus should combine several types of syllabi that do not exclude but complement each other.

Among the syllabi organizational forms for teaching a foreign language abroad we can distinguish the linear, cyclical and modular types.

The linear syllabus involves such an order in presenting and exercising the linguistic material when every new course unit introduces and trains the new language material which practically will not be repeated.

The syllabus of a modular type-the modular syllabus - according to which the course consists of several modules. Every module is independent and their complex represents a unity aimed at achieving the education goals and objectives. An important condition for the syllabus design based on a modular principle is the role of every module in the ultimate goals of the course.

The spiral syllabus / cyclical syllabus involves the use of the selected language material grouped in cycles. Such an organization of the syllabus and teaching process ensures repetition of the linguistic material from cycle to cycle and contributes to its thorough memorizing (Kolesnikova \& Dolgina, 2001).

Many foreign researchers (Lamb, D. Newnan, J. Yalden and others) agree that these syllabi should include the following sections: the educational objectives and tasks ; the content, language and speech material that can be represented in different ways according to the approach and principles of education; the tasks and the methods of teaching and learning that are used by the teacher and students; the requirements to the command of language ; various types and forms of monitoring and assessment of the level of training including self-esteem and self-control; the teaching materials (Yalden, 1995; Nunan \& Lamb, 1996).

Having analyzed the standards of language education, the foreign language syllabus, having revealed the modern requirements to them we find it necessary to analyze the national and foreign textbooks and manuals for the students of economic faculties in order to compare their content.

The following national English manuals and teaching aids for the university students of economics have been analyzed: The English course for the students of Finance and Economy (Lyubimtseva, 2009), The manual of English for the students of economics (Bolshakova, 2004), The Fundamentals of Economics and Business: English study guide (Sheveleva, 2012), The Textbook of English for business communication in 6 sets (Dudkina \& Pavlova, 2007), New Business English. The course of business vocabulary in English (Kumarova, 1998),A handbook of a businessman (English language course for business and business communication (Lukyanov, 2008),Business English (Fedotova, 2003), Business English Course (Bogatsky \& Dyukanova, 2003).

The analysis of the abovementioned national textbooks and manuals has allowed to identify the most common topics: "The future profession", "English-speaking partner countries", "A Modern Company", "Business Types", "Management", "Exchange and Securities", "Banks and banking services", "Accounting", "The Etiquette of business communication", "Wholesale and retail trade", "A Bargain, Business negotiations", "Shipping documents", "Business telephone talks" and others.

But the rare, hardly represented in the manuals for economists are the themes that imply the core values of human civilization in the process of internationalization of all spheres of human life; the topics affecting the global challenges of the modern multilingual and multicultural world; the international topics circulating in cross-cultural communication of the specialists in economics; the topics operating in the field of professional scientific activity in economics in terms of international cooperation.

Thus, the performed analysis showed that the majority of national textbook sand manuals does not reflect the international component of the foreign language teaching syllabus, that accordingly, does not comply with the requirements of the education internationalization. This fact brings to the conclusion that the content of the national manuals and teaching aids for teaching a foreign language does not fully meet the students' demand in personal and professional self-development in the conditions of internationalization of all spheres of human activity. 


\section{Results}

As a result of the analysis of foreign and domestic experience in structuring a foreign language teaching syllabus we have identified the requirements to it according to the education internationalization processes:

Firstly, the syllabus should reflect the new scientifically_-grounded concept of teaching foreign languages, be focused on new historical conditions, the needs of the present day when education should transform into a mechanism to develop an individual and thus into an effective factor of the society development.

Secondly, the syllabus should be flexible; it should set the targets, lay down the fundamental guidelines to achieve the objectives, provide choice, be open to change and adapt to the specific conditions.

Third, it should be more instrumental aimed at the target and the dynamics of its achievement. Thus, the program must set the parameters for the organization of the foreign language teaching and serve as an instrument of control.

Fourth, the syllabus should really encourage the teacher to be creative and not just declare this idea since other teachers can create their specific modification of the syllabus on its basis.

Fifth, it should contribute to the improvement of (widening and deepening) general, vocational as well as language education of the students by means of foreign language as well as upbringing their personality

Sixthly, it must contribute, inter alia to enlarging the students' scope, academic mobility, social activity, forming their emotional and value-conscious attitude to the world taking into account the realities occurring in global environmental, economic and socio-political processes.

Seventh, the syllabus should improve general, communicative, special learning skills of the students, develop their independence, intellectual creativity, ability to cooperate, moral stability, ingenuity and persistence in achieving the goals and need for personal growth.

Eighth, the syllabus should include the international component that is directed towards language training of a specialist who can perform professional duties in international and multicultural space, which allows the international comparison and correlation of the education results at various levels, increases the attractiveness of the university for foreign students, contributes to the internationalization of knowledge and formation of trans-cultural skills, enables the students to be educated in accordance with the international standards without leaving his/her university.

The main didactic requirements for a foreign language teaching syllabi include: consistency in presenting the linguistic material within the levels of education; continuity in designing a foreign language syllabus; a modular design of the educational material, the training programs and the establishment of a system of integrated courses; providing deep, flexible language skills and knowledge achieved by the increased volume of speech practice both in terms of perception (reading and listening) and reproduction (speaking and creative writing); significant expansion of the scope of receptive and potential vocabulary and grammatical phenomena that the students can independently understand while reading and listening; enriching the active vocabulary minimum, in particular, in the field of economics; the targeted training of the students to use this vocabulary to solve communication problems.

The analysis has revealed the international component of the foreign language syllabus including:

- The motives, values, feelings and emotions that enhance motivation to learn a foreign linguistic culture through creation of natural communication motifs, development of the value orientations and emotional evaluation of the students' attitudes to the ongoing process of internationalization, as well as their independence and activity in intercultural interaction;

- The knowledge that 1) interpret the core values of human civilization in internationalization of all spheres of human activity ("Values and Culture", "Spirituality and morality", "Freedom and Responsibility", and others.); 2) affect the global challenges of the modern multicultural and multilingual world reflecting the interdependence between the nations and peoples and aimed at peace education ("The Environmental Ecology ", "The Gender and demographic problems of today", "Racial discrimination", "National extremism", etc.); 3) function in the process of intercultural communication of the specialists in economics ("Foreign trade and currency", "International Marketing", "International trade negotiations", etc.); 4) are used in the scientific field of professional activity of the specialists in economics in terms of international cooperation ("International Scientific Research in Economics", "International scientific conferences," etc.), as well as cross-cultural and socio-cultural knowledge of the geography, ethnography, economy, politics and culture; knowledge of cross cultural and communication norms, household and cultural realities, social and cultural stereotypes of verbal 
behavior in a foreign language necessary for interdisciplinary acquaintance with the socio-cultural pattern of Europe and other countries in the context of the cultures dialogue, of social interaction in the course of internationalization in all spheres of human activity;

- Skills: communicative skills necessary to provide intercultural communication in terms of the internationalization processes; the ability to think in a comparative perspective and change self-perception; the ability to view their native country in cross-cultural perspective; the ability to choose the ways of interaction with the world, trans-cultural skills.

\section{Conclusion}

The analysis of national syllabi, textbooks and teaching materials has shown that the content-related aspect of teaching a foreign language in the light of internationalization of education is insufficient. In this regard, we have analyzed the foreign syllabi and manuals which allowed to highlight the international component of their content including: motives, value-based targets and emotions that enhance motivation to learn a foreign linguistic culture, development of value-based attitudes and students' emotional evaluation of the ongoing process of internationalization; the knowledge interpreting the basic values of human civilization in conditions of internationalization of all spheres of human activity; knowledge associated with the global issues of modern multilingual and multicultural world; knowledge functioning in the process of intercultural communication of the specialists in economics and used in the scientific field of their specialty; cross-cultural and socio-cultural knowledge; communication skills necessary to provide intercultural communication in terms of internationalization processes; the ability to think in a comparative perspective, to change self-perception, to view the country in the cross-cultural aspect, to choose the way of interaction with the world as well as trans-cultural skills.

Designing a foreign language teaching syllabus in higher education at present stage should: be performed in accordance with the social order; take into account the relevant professional knowledge, skills and characteristics of a specialist in economics; be determined by the dynamics of the "linguistic picture of the world"; meet the qualification requirements of the future specialty in the field of foreign language; reflect a distinct communicative, person-oriented and professional focus on foreign language teaching.

\section{References}

Bogatsky, I. S., \& Dyukanova, N. M. (2003). Business English Course (p. 121). Moscow.

Bolshakova, Y. (2004). Textbook of English for students of economics (p. 156). Kazan.

Dudkina, G. A., \& Pavlova, M. V. (2007). Textbook of English for business communication in 6 parts (p. 506). Moscow.

Ellis, R. (1997). SLA Research and Language Teaching. Oxford University Press.

Fedotova, O. L. (2003). Business English (p. 34). Kazan.

Galskova, N. D. (2000). Modern methods of teaching foreign languages. In Handbook for Teachers (p. 165). Moscow.

Grigoryeva, E. V., Leyfa, I. I., Yatsevich, L. P., Demyanenko, M. A., Makovey, N. V., Pavlushkina, T. V., \& Masalimova, A. R. (2015). Designing a Structure of the Modular Competence-Based Curriculum and Technologies for Its Implementation into Higher Vocational Institutions. Review of European Studies, 7(1), 123-129.

Gutman, Y. Y., Masalimova, A. R., Shaidullina, A. R., Nizamieva, A. M., \& Mukhamadieva, A. H. (2014). Foreign language discipline integrative potential in the students' research competence development. American Journal of Applied Sciences, 11, 1099-1103. http://dx.doi.org/10.3844/ajassp.2014.1099.1103

Hutchinson, T., \& Waters, A. (1987). English for Specific Purposes (p. 217). Cambridge University Press.

Ivanenko, N. A., Akhmetov, L. G., Lavrentiev, S. Y., Kartashova, E. P., Lezhnina, L. V., Tzaregorodtzeva, K. A., \& Khairullina, E. R. (2015). Features of Modeling the Formation of Teaching Staff Competitiveness. Review of European Studies, 7(3), 37-42. http://dx.doi.org/10.5539/res.v7n3p37

Ivanov, V. G., Shaidullina, A. R., Drovnikov, A. S., Yakovlev, S. A., \& Masalimova, A. R. (2015). Regional Experience of Students' Innovative and Entrepreneurial Competence Forming. Asian Social Science, 11(1), $35-40$.

Jordan, R. R. (1997). English for Academic Purposes: A Guide and Resourse Book for Tearchers. Camebridge. http://dx.doi.org/10.1017/CBO9780511733062 
Kolesnikova, I. L., \& Dolgina, O. A. (2001). English-Russian terminology guide on teaching foreign languages (p. 224). Saint Petersburg: Cambridge University Press.

Kumarova, M. M. (1998). New Business English. In The course of business vocabulary of the English language (p. 78). Moscow.

Lopatina, O. V., Borisov, A. M., Leyfa, I. I., Galimzyanova, I. I., Yatsevich, L. P., Demyanenko, M. A., \& Masalimova, A. R. (2015). Role of foreign language teacher shaping students' research skills.Asian Social Science, 11(4), 135.

Lopatina, O. V., Fassakhova, G. R., Akhmetova, L. A., Gatin, R. G., Yarullina, A. S., Nikishina, S. R., \& Khairullina, E. R. (2015).The Technology of Forming the Students' Research Competence in the Process of Learning a Foreign Language. Asian Social Science, 11(3), 152-157.

Lukyanova, N. A. (2008). Handbook businessman (English language course for business and forms of business communication (p. 95). Moscow.

Lyubimtseva, S. N. (2009). The English course for the students of Finance and Economy (p. 123). Moscow.

Masalimova, A. R., Ikramova, G. D., Shaidullina, A. R., Gubaidullina, G. T., \& Apraksina, N. D. (2014). Distant in-company foreign language learning involving university student-tutors. American Journal of Applied Sciences, 11, 1123-1127. http://dx.doi.org/10.3844/ajassp.2014.1123.1127

Nunan, D., \& Lamb, C. (1996). The Self-Directed Teacher. In Managing the Learning Process (pp. 9-10).

Nunan, D. (1998). Language Teaching Methodology: A Textbook for Teachers. Prentice Hall.

Odlin, T. (1994). Perspectives on Pedagogical Grammar (p. 322). Cambridge: CUP. http://dx.doi.org/10.1017/CBO9781139524605

Sakhieva, R. G., Khairullina, E. R., Khisamiyeva, L. G., Valeyeva, N. Sh., Masalimova, A. R., \& Zakirova, V. G. (2015). Designing a Structure of the Modular Competence-Based Curriculum and Technologies for Its Implementation into Higher Vocational Institutions. Asian Social Science, 11(2), 246-251.

Sakhieva, R. G., Ibatullin, R. R., Biktemirova, M. K., Valeyeva, G. K., Pchelina, O. V., Valeyeva, N. Sh., Minsabirova, V. N., \& Khairullina, E. R. (2015). The Essential, Objective and Functional Characteristics of the Students' Academic Mobility in Higher Education. Review of European Studies, 7(3), 335-340. http://dx.doi.org/10.5539/res.v7n3p335

Shaidullina, A. R., Krylov, D. A., Sadovaya, V. V., Yunusova, G. R., Glebov, S. O., Masalimova, A. R., \& Korshunova, I. V. (2015). Model of Vocational School, High School and Manufacture Integration in the Regional System of Professional Education. Review of European Studies, 7(1), 63-67.

Sheveleva, S. A., \& Stogov, V. E. (2012). Foundations of Economics and Business: A tutorial (p. 496). Moscow.

Valeeva, R. A., Koroleva, N. E., \& Sakhapova, F. K. (2014). Civic education of the technical university students in foreign language classes. Review of European Studies, 7(1), 176-181. http://dx.doi.org/10.5539/res.v7n1p176

Willis, D. (1990). The Lexical Syllabus: A New Approach to Language Teaching. London: Collins ELT.

Yalden, J. (1995). Principles of Course Design for Language Teaching (p. 207). New York: Cambridge University Press.

\section{Copyrights}

Copyright for this article is retained by the author(s), with first publication rights granted to the journal. This is an open-access article distributed under the terms and conditions of the Creative Commons Attribution license (http://creativecommons.org/licenses/by/3.0/). 